03

\title{
Особенности формирования эпитаксиальных слоев InAsSbP на подложке InAs методом газофазной эпитаксии из металлоорганических соединений
}

\author{
(С) К.Д. Моисеев ${ }^{1}$, В.В. Романов ${ }^{1}$, Ю.А. Кудрявцев ${ }^{2}$ \\ ${ }^{1}$ Физико-технический институт им. А.Ф. Иофре РАН, \\ Санкт-Петербург, Россия \\ ${ }^{2}$ Отделение твердотельной электроники Центра исследований и передового обучения \\ Национального политехнического института, \\ Мехико, Мексика \\ E-mail: mkd@iropt2.ioffe.ru
}

(Поступила в Редакцию 18 мая 2016 г.)

\begin{abstract}
Эпитаксиальные слои в системе твердых растворов InAs $\operatorname{In-y}_{1-y} \mathrm{Sb}_{y} \mathrm{P}_{x}$ в диапазоне составов $0<x<0.72$ получены на подложке $\operatorname{InAs}(001)$ методом газофазной эпитаксии из металлоорганических соединений (МОГФЭ). Послойный анализ полученных структур с помощью метода масс-спектрометрии вторичных ионов показал градиентное изменение состава вдоль направления наращивания. Резкое изменение состава на гетерогранице слой/подложка наблюдалось для четверных твердых растворов InAsSbP благодаря присутствию радикалов соединений мышьяка в газовой фазе. При эпитаксиальном наращивании на подложку InAs в системе твердых растворов InAsSbP методом МОГФЭ уменьшение содержания мышьяка в твердой фазе менее $(1-x-y)<0.3$ приводило к подавлению градиентности осаждаемого слоя, а также и подавлению колебаний состава в начальном переходном слое.
\end{abstract}

Работа выполнена при поддержке проекта РФФИ № 14-02-01102.

\section{1. Введение}

Эпитаксиальные слои в системе твердых растворов $\operatorname{InAs}_{1-x-y} \mathrm{Sb}_{y} \mathrm{P}_{x}$, изопериодные с подложкой InAs, были получены в широком диапазоне составов $0<x<0.72$, когда в процессе наращивания атомы мышьяка в кристаллической рещетке последовательно замещались атомами фосфора и сурьмы [1-3]. При этом могут быть использованы различные эпитаксиальные методы, такие как жидкофазная эпитаксия и газофазная эпитаксия из металлоорганических соединений (МОГФЭ). Если для метода жидкофазной эпитаксии максимальное значение содержания фосфора в твердой фазе $x=0.31$ ограничено областью существования составов, определенной по условиям молекулярности и спинодального распада твердого раствора, то, применяя метод МОГФЭ, удалось достичь значения $x=0.72$. Отличительной особенностью твердых растворов, изопериодных по параметру кристаллической решетки с арсенидом индия, является неизменное соотношение фосфора и сурьмы в твердой фазе, равное $x=2.1 y$ [4]. Данная особенность предполагает некоторую степень самоорганизации твердого раствора в процессе наращивания за счет пропорционального встраивания атомов $\mathrm{Sb}$ и $\mathrm{P}$ в кристаллическую решетку эпитаксиального слоя. В предыдущей работе мы предложили модель роста эпитаксиального слоя InAsSbP, изоморфного с подложкой InAs, при заданном значении соотношения концентрации фосфора и сурьмы в твердой фазе [3]. Была предсказана схематическая структура, состоящая из трех градиентных участков (включая переходные слои в начале и конце эпитаксиального процесса), при условии введения дополнительного параметра мозаичности $M$. Настоящая работа является продолжением начатых исследований и представляет экспериментальные доказательства предложенной модели.

\section{2. Технология изготовления структур и методика экспериментов}

Эпитаксиальные слои четырехкомпонентного твердого раствора $\operatorname{InAs}_{1-x-y} \mathrm{Sb}_{y} \mathrm{P}_{x}$ в интервале составов $0.4<x<0.72$ наращивались на подложки InAs, ориентированные в плоскости (001), методом МОГФЭ в кварцевом реакторе горизонтального типа при атмосферном давлении. Источниками компонентов третьей и пятой групп для эпитаксиального роста являлись триметилиндий (TMIn), триметилстибин (TMSb), третбутиларсин (tBAs) и фосфин $\left(\mathrm{PH}_{3}\right)$, разбавленный до концентрации 20\% в водороде. Рост твердого раствора InAsSbP проводился при температуре $510^{\circ} \mathrm{C}$ при соотношении реагентов пятой и третьей групп более 10. Изменение состава твердого раствора осуществлялось только за счет изменения количества третбутиларсина, которое влияло на содержание фосфина в газовой фазе, при этом соотношение между триметилстибином и фосфином в газовой фазе $\left(\mathrm{TMSb} / \mathrm{PH}_{3}\right)$ поддерживалось постоянным для всех составов газовой фазы. Введение третбутиларсина производилось пропорционально: увеличивалось равными долями для каждого последующего состава 
газовой фазы, который соответствовал определенному составу эпитаксиального слоя. Использование третбутиларсина обеспечивало хорошую прогнозируемость заданного состава при наращивании твердого раствора InAsSbP c высоким содержанием фосфора $(x>0.4)$. Подробности технологии наращивания приведены в [3].

Послойный анализ структур проводился методом масс-мпектрометрии вторичных ионов (ВИМС) на времяпролетном масс-спектрометре TOF-SIMS V от ION-TOF GmbH (Германия). Травление участка поверхности размером $300 \times 300 \mu \mathrm{m}$ осуществлялось пучком ионов цезия с энергией $1 \mathrm{keV}$ и углом падения $45^{\circ}$ относительно нормали к поверхности. Центральная часть кратера травления анализировалась с использованием пульсирующего жидкометаллического источника ионов висмута: ток пучка $\mathrm{Bi}_{3}^{+}$составлял около $0.4 \mathrm{pA}$, зона анализа $-100 \times 100 \mu \mathrm{m}$. Для минимизации матричного эффекта и проведения количественного анализа твердых растворов мы использовали так называемый $\mathrm{Cs} M$-режим: анализ вторичных ионных кластеров $\mathrm{Cs} M^{+}$, где $M$ - анализируемый элемент. В случае мышьяка и фосфора анализировались ионные кластеры $\mathrm{Cs}_{2} \mathrm{As}^{+}$ и $\mathrm{Cs}_{2} \mathrm{P}^{+}$соответственно. Факторы относительной чувствительности определялись относительно сигнала $\mathrm{Cs}^{2+}$ в двухкомпонентных полупроводниковых соединениях: InAs, InSb и InP. Глубина кратеров травления измерялась профилометром Dektak XT фирмы Bruker.

\section{3. Результаты и обсуждение}

На рис. 1 приведены типичные профили распределения концентрации компонентов твердого раствора InAsSbP вдоль направления эпитаксиального наращива-

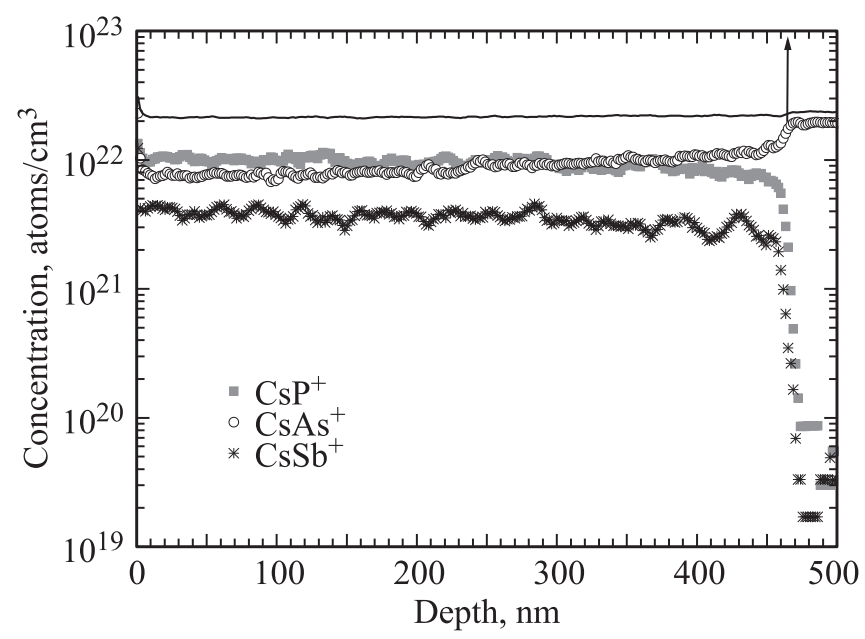

Рис. 1. Экспериментальные ВИМС-профили распределения компонентов в эпитаксиальном слое четверного твердого раствора $\operatorname{InAs} \mathrm{s}_{0.40} \mathrm{Sb}_{0.17} \mathrm{P}_{0.43}$ вдоль направления наращивания для образца SNS-6. Нулевая отметка соответствует положению границы раздела слой InAsSbP/воздух. Стрелкой отмечено положение гетерограницы InAsSbP/InAs(подложка). ния при осаждении на подложку InAs из газовой фазы, обогащенной соединениями фосфора, сурьмы, мышьяка и индия. Профиль распределения индия (сплошная линия) демонстрирует практически постоянное значение концентрации во всем интервале толщин и одну особенность, которая позволяет определить положение гетерограницы InAsSbP/InAs и, следовательно, оценить толщину полученного слоя. Для данного образца граница раздела двух полупроводников находится вблизи отметки $d=465 \mathrm{~nm}$, отсчитанной от поверхности эпитаксиального слоя. В отличие от индия - элемента третьей группы, который присутствует как в подложке, так и в твердом растворе, профили элементов пятой группы (фосфора, сурьмы и мышьяка) отражают заметные изменения концентрации каждого элемента вдоль направления эпитаксиального наращивания. При этом концентрации фосфора и сурьмы возрастают, а концентрация мышьяка падает. Начало уменьшения концентрации мышьяка совпадает с началом роста эпитаксиального слоя, что также указывает на положение гетерограницы InAsSbP/InAs.

Следует сразу отметить различия в резкости изменения профиля вблизи гетерограницы слой/подложка для случаев четверного и тройного твердых растворов (рис. 2 и 3). Образец SNS-3 (тройной твердый раствор $\left.\mathrm{InSb}_{0.27} \mathrm{P}_{0.73}\right)$ демонстрирует плавное изменение состава в начальной области осаждаемого эпитаксиального слоя (в интервале толщин порядка $120 \mathrm{~nm}$ ), что может быть вызвано диффузионным подмешиванием атомов мышьяка в твердой фазе из подложки InAs через гетерограницу в объем твердого раствора InSbP вследствие отсутствия соединений мышьяка в газовой фазе в процессе наращивания. Для образцов с четверными твердыми растворами $\mathrm{InAs}_{1-x-y} \mathrm{Sb}_{y} \mathrm{P}_{x}$ (SNS-4 и SNS-6) характерно резкое изменение по составу на гетерогранице для элементов пятой группы (в интервале $12 \mathrm{~nm}$ ) благодаря присутствию радикалов соединений мышьяка в газовой фазе при наращивании эпитаксиального слоя.

В настоящей работе экспериментально показано градиентное изменение состава в полученных слоях, предсказанное в работе [3]. Как видно из рис. 2, основная часть слоя четверного твердого раствора представляла собой структуру с плавным возрастанием концентрации фосфора вдоль направления роста, выходящим на насыщение при достижении определенного значения. Это достигалось за счет эффекта самоорганизации твердой фазы в процессе наращивания эпитаксиального слоя $\operatorname{InAs}_{1-x-y} \mathrm{Sb}_{y} \mathrm{P}_{x}$, что было обусловлено выбранной величиной соотношения $\mathrm{TMSb} / \mathrm{PH}_{3}$ в газовой фазе. По мере уменьшения содержания мышьяка в твердой фазе градиент возрастания концентрации фосфора уменьшался. В предельном случае (при отсутствии мышьяка в газовой и, следовательно, в твердой фазе) для тройного твердого раствора концентрация фосфора демонстрировала обратную динамику при толщинах свыше $300 \mathrm{~nm}$ от границы раздела слой/подложка. Наблюдаемое возрастание содержания фосфора и сурьмы в твердой фазе 


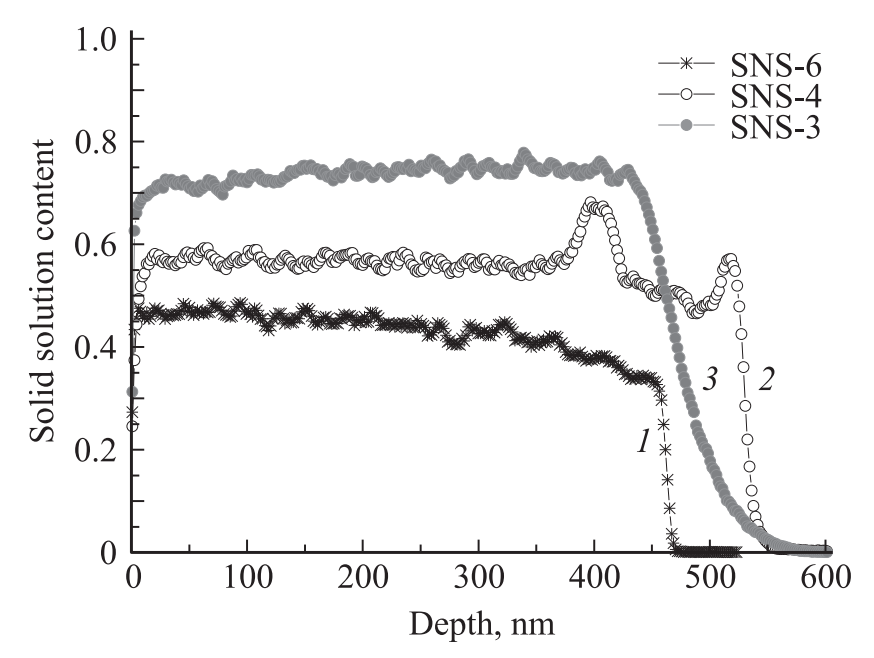

Рис. 2. Профили концентрации фосфора в твердой фазе для образцов с заданным средним значением: $x=0.43(1), 0.56$ (2) и 0.73 (3).

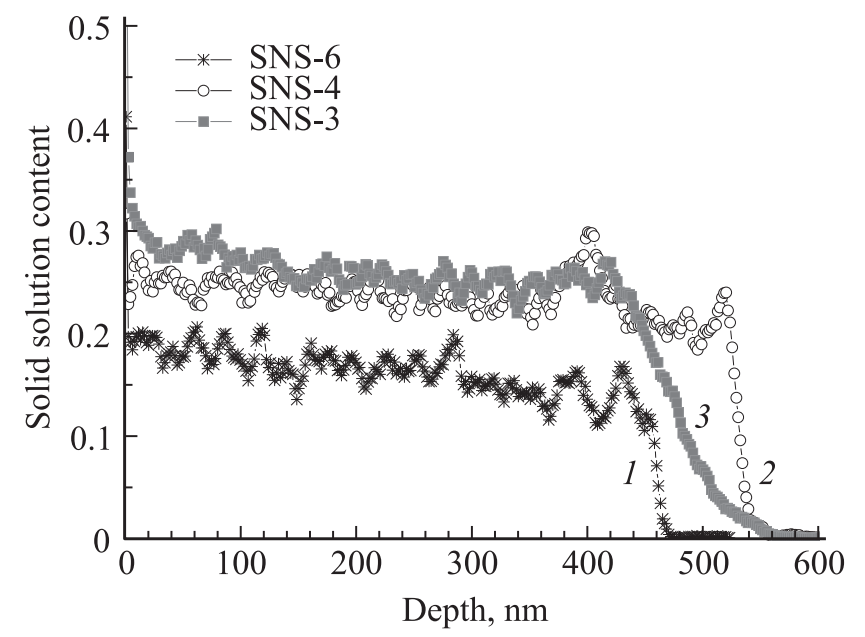

Рис. 3. Профили концентрации сурьмы в твердой фазе для образцов с заданным средним значением: $x=0.17(1), 0.23$ (2) и 0.27 (3).

четверного твердого раствора было обусловлено более быстрым обеднением приповерхностного слоя радикалами мышьяка по сравнению с другими элементами пятой группы.

Известно, что количество определенного элемента пятой группы в твердой фазе лимитируется самым медленным из процессов, которые протекают при наращивании твердого раствора (поверхностные реакции, диффузия адатомов по поверхности, диффузия радикалов через приповерхностный слой и др.) [5]. В начальный момент осаждения состав заданной газовой фазы над поверхностью подложки определяется поверхностными реакциями. Затем, при наращивании, с началом обеднения приповерхностного слоя элементами пятой группы диффузия через приповерхностный слой становится самым медленным процессом, который и ограничивает ско- рость доставки компонентов для роста эпитаксиального слоя. При дальнейшем обеднении приповерхностного слоя радикалами пятой группы скорость диффузии этих элементов постепенно будет падать до тех пор, пока не станет соизмеримой со скоростью доставки металлоорганических соединений в зону наращивания. Поскольку, как отмечалось выше, обеднение радикалами мышьяка приповерхностного слоя происходит намного быстрее, формирование диффузионного канала этого элемента (на фоне диффузионных процессов других элементов пятой группы) будет значительно влиять на состав твердой фазы. Как видно из рис. 1, плавное падение содержания мышьяка и как следствие возрастание сурьмы и фосфора в твердой фазе наращиваемого слоя при толщинах более $300 \mathrm{~nm}$ связаны с увеличением времени доставки радикалов мышьяка через приповерхностный слой к поверхности роста. Согласно данным рис. 3, концентрация сурьмы также постоянно возрастала вдоль направления роста. Однако соотношение концентраций фосфора и сурьмы в четверном твердом растворе почти не менялось и колебалось вблизи значения $x / y=2.4$, которое задавалось условием изоморфности твердого pacтвора InAsSbP с подложкой арсенида индия.

На примере четырехкомпонентного твердого раствора $\mathrm{InAs}_{0.40} \mathrm{Sb}_{0.17} \mathrm{P}_{0.43}$ (SNS-6) наращиваемый эпитаксиальный слой можно схематически представить как структуру, состоящую как минимум из трех градиентных участков (включая переходные слои в начале и конце эпитаксиального процесса). Если существование переходного слоя в конце эпитаксиального процесса легко объяснить как продукт остаточных реакций в газовой фазе при выключении подачи реагентов в реактор, то природа переходного слоя в начале наращивания, в момент контакта с подложкой, немного сложнее. Особенность технологии наращивания четверного твердого раствора InAsSbP на поверхность $\operatorname{InAs}(100)$ при атмосферном давлении, когда время доставки реагентов к зоне роста достаточно велико, заключается в том, что подача триметилиндия в реактор производится с небольшой задержкой $(5-10 \mathrm{~s})$ после напуска источников пятой группы для препятствования осаждению элементарного индия на поверхность подложки. В отсутствие атомов индия над поверхностью подложки в основном протекают абсорбционнодесорбционные процессы с участием элементов пятой группы. Это приводит к тому, что формирование потока элемента третьей группы к поверхности подложки происходит на фоне уже сформированных избыточных парциальных давлений элементов пятой группы над поверхностью подложки. Следовательно, диффузионные потоки элементов пятой группы существуют до начала осаждения, и эти потоки сильно насыщают адатомами приповерхностный слой, выводя систему из равновесия.

После напуска триметилиндия в реактор запускается процесс роста твердого раствора, за счет которого система пар-твердое тело стремится к равновесию. При этом происходит обеднение элементами пятой 


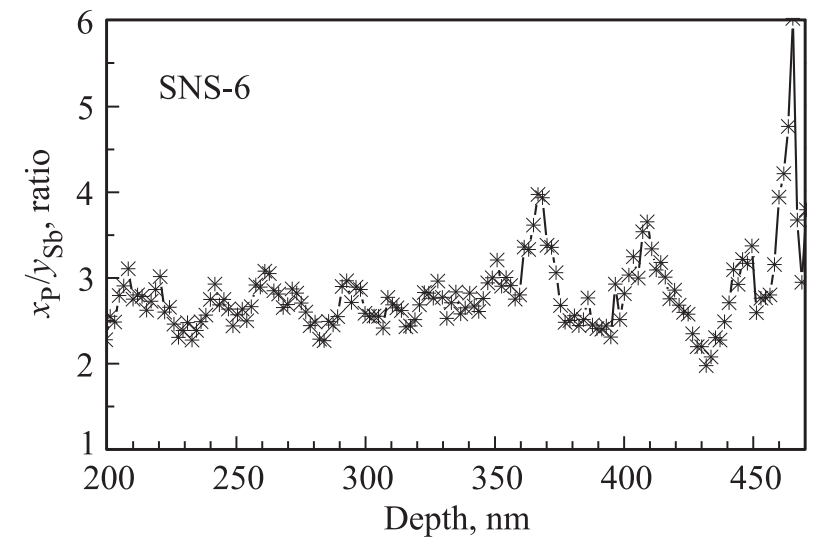

Рис. 4. Изменение состава твердого раствора в переходном слое при начальном наращивании эпитаксиального слоя четверного твердого раствора $\operatorname{InAs} \mathrm{s}_{0.40} \mathrm{Sb}_{0.17} \mathrm{P}_{0.43}$.

группы приповерхностного слоя газовой фазы и начинают формироваться диффузионные потоки. В условиях атмосферного давления фронт потока реагента индия может сильно размываться, и концентрация адатомов индия у поверхности подложки в начале эпитаксиального процесса возрастает постепенно, что приводит к увеличению длительности переходных процессов в начальный момент роста эпитаксиального слоя. Как видно из рис. 4, начальный переходный слой характеризуется достаточно сильными колебаниями по составу твердой фазы, что связано с изменением состава газовой фазы на поверхности при формировании диффузионного потока адатомов индия к подложке. Таким образом, на начальном этапе наращивания, когда система пар-твердое тело сильно выведена из равновесных условий, бо́льшую вероятность вхождения в твердую фазу имеет мышьяк вследствие наименьшей величины равновесного парциального давления над рабочей поверхностью слоя среди компонентов пятой группы газовой фазы [6].

При последующем наращивании над поверхностью растущего слоя давление паров радикалов мышьяка падает, что приводит к уменьшению скорости встраивания мышьяка в твердую фазу. В этот момент в твердую фазу начинает активно встраиваться фосфор вследствие наибольшего коэффициента сегрегации соединения InP (по отношению к остальным бинарным соединениям на основе индия) с последующим вхождением сурьмы благодаря эффекту самоорганизации изоморфных твердых растворов InAsSbP. Большая скорость встраивания фосфора приводит к более быстрому истощению приповерхностного слоя адатомами фосфора по сравнению с адатомами сурьмы и приводит к условиям, при которых возрастает скорость встраивания сурьмы. Восполнение концентрации соединений фосфора в газовой фазе происходит за счет потока доставки в реактор. В данном случае в условиях пониженных температур эпитаксии скорость доставки соединений фосфора была меньше скорости диффузии адатомов фосфора через приповерхностный слой над подложкой. Таким образом, во время переходных процессов, когда формируется поток источника индия над поверхностью подложки, в растущем слое содержание мышьяка резко падает, а фосфора растет (рис. 1). Также следует отметить, что на начальном этапе осаждения встраивание фосфора в твердую фазу эпитаксиального слоя происходит значительно быстрее, чем встраивание сурьмы, что приводит к истощению приповерхностного слоя адатомами фосфора по сравнению с адатомами сурьмы, и последующие наращенные слои обогащены сурьмой. Затем содержание сурьмы в твердом растворе падает вследствие истощения приповерхностного слоя уже адатомами сурьмы, а содержание фосфора возрастает.

Как видно из рис. 4, на начальном этапе эпитаксиального наращивания из-за разной скорости формирования диффузионных потоков фосфора и сурьмы через приповерхностный слой сегрегация данных элементов происходит с различной скоростью, что приводит к росту четверного твердого раствора, у которого состав твердой фазы в пределах переходного слоя может сильно меняться в диапазоне нескольких нанометров. Сначала формируется эпитаксиальный слой, обогащенный фосфором, затем содержание сурьмы в последующем слое возрастает по отношению к фосфору, а потом снова падает, что может приводить к модуляции состава в ограниченном пространстве и возможному формированию квантовой ямы шириной 5-10 nm. При этом речь может идти о квантовой яме типа I в ее классическом варианте, когда более узкозонный слой (обогащенный сурьмой) вставлен между двумя более широкозонными слоями (обогащенными фосфором) и существуют потенциальные барьеры одновременно для электронов в зоне проводимости и для дырок в валентной зоне.

Изменение химии поверхности также приводит к возрастанию или падению скорости сегрегации определенных атомов четверного твердого раствора, что в свою очередь приводит к изменению скорости диффузионных потоков этих элементов, усиливая или ослабляя колебание состава твердой фазы. Этот эффект оказывает значительное влияние, когда диффузионные потоки только начинают формироваться, а времена диффузии элементов еще соизмеримы с временами поверхностных реакций над растущем слоем. С увеличением диффузионных каналов время диффузии увеличивается, и система становится более инертной, что приводит к затуханию колебаний состава твердого раствора вдоль направления эпитаксиального наращивания, что и наблюдается в эксперименте для значений толщин слоя более $d=300 \mathrm{~nm}$ от подложки.

При наращивании на подложку InAs в системе твердых растворов InAsSbP методом МОГФЭ уменьшение содержания мышьяка в твердой фазе менее 0.3 приводит не только к уменьшению градиентности получаемого слоя, но и к подавлению колебаний состава в начальном переходном слое (рис. 5). Выше было показано, что наиболее активно (по сравнению с остальными 


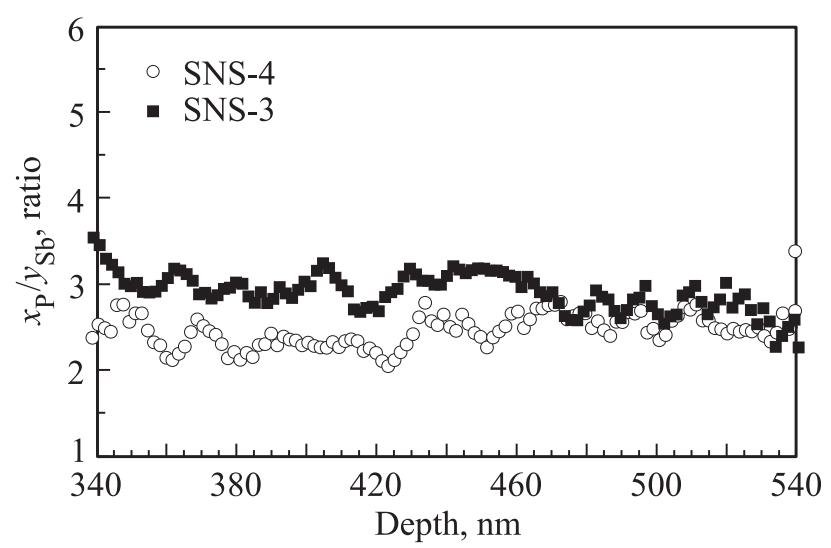

Рис. 5. Изменение состава твердого раствора в переходном слое при начальном наращивании эпитаксиальных слоев четверного $\operatorname{InAs}_{0.18} \mathrm{Sb}_{0.26} \mathrm{P}_{0.56}$ и тройного $\operatorname{InSb}_{0.27} \mathrm{P}_{0.73}$ твердых растворов при содержании мышьяка в твердой фазе $z=1-x-y<0.25$.

компонентами пятой группы газовой фазы), в твердую фазу встраивается мышьяк, тогда как скорости встраивания фосфора и сурьмы в твердую фазу сопоставимы. Поэтому наращивание четверных твердых растворов с содержанием мышьяка в твердой фазе свыше 0.4 сопряжено с образованием на гетерогранице InAs/InAsSbP переходного слоя модулированного состава в виде одной или нескольких квантовых ям, что может оказывать существенное влияние на электрические и люминесцентные свойства гетероструктур, сформированных на основе данных слоев.

\section{4. Заключение}

Таким образом, была экспериментально подтверждена предложенная нами ранее [3] модель градиентного изменения состава в эпитаксиальных слоях в системе твердых растворов InAsSbP при наращивании их на подложку InAs методом МОГФЭ. Было показано, что изменения концентрации фосфора и сурьмы происходят синхронно, что обусловлено эффектом самоорганизации изоморфных твердых растворов InAsSbP, обогащенных арсенидом индия. При этом количество мышьяка в твердой фазе четырехкомпонентного твердого раствора InAsSbP определяет величину градиента по составу для каждого конкретного эпитаксиального слоя. Более того, наращивание четверных твердых растворов с содержанием мышьяка в твердой фазе свыше 0.4 сопряжено с образованием на гетерогранице InAs/InAsSbP переходного слоя модулированного состава в виде одной или нескольких квантовых ям.

Авторы выражают благодарность Т.Б. Поповой за проведение измерений для исследованных гетероструктур.

\section{Список литературы}

[1] Т.И. Воронина, Т.С. Лагунова, К.Д. Моисеев, Н.А. Прокофьева, Т.Б. Попова, М.А. Сиповская, В.В. Шерстнев, Ю.П. Яковлев. ФТП 25, 1639 (1991).

[2] В.В. Романов, Э.В. Иванов, А.Н. Именков, Н.М. Колчанова, К.Д. Моисеев, Н.Д. Стоянов, Ю.П. Яковлев. Письма в ЖТФ 27, 14, 80 (2001).

[3] В.В. Романов, М.В. Байдакова, К.Д. Моисеев. ФТП 48, 753 (2014).

[4] К.Д. Моисеев. Автореф. канд. дис. ФТИ им. А.Ф. Иоффе РАН, СПб. (1995). 18 c.

[5] G.B. Stringfellow. Organometallic vapor-phase epitaxy: theory and practice. 2nd ed. Academic Press, San Diego, USA (1999). $599 \mathrm{p}$.

[6] A. Koukitu, H. Seki. J. Cryst. Growth 76, 233 (1986). 